would be cleared. Hence the problem is essentially one for assistance as a post-war measure.

It is estimated from Korringa's data that dried protein constitutes about 1 per cent of the net weight of slipper-limpets, and as thirty tons of limpets could easily be dredged in a day with appropriate gear, a considerable daily quantity of food-material could be produced; the rate of supply could be adjusted within wide limits to meet the requirements of the manufacturing process.

The object of this communication is to direct the attention of the various bodies likely to be interested to the problem with the view of facilitating early action. These bodies are: Ministry of Agriculture and Fisheries as representatives of public oyster beds, and oyster cultivators; Ministry of Food, representing untapped sources of food supply; Department of Scientific and Industrial Research, as concerned in processes of food manufacture; Development Commission, as the body interested in researches dealing with improvements in fisheries; as well as private manufacturers of food products, and representatives of the oyster cultivators whose beds require clearing.

It is obvious that if these limpets could be used as food there would result the double advantage of contributing to the food stocks of Europe and helping the oyster farmers to clear their beds of this pestilent but extremely interesting immigrant from America.

I am indebted to Dr. P. Korringa for recent information relating to the Dutch oyster beds.

Department of Zoology, J. H. ORTON.

University of Liverpool. Sept. 1.

1 Nature, 145, 708 (1940).

${ }^{2}$ Visscher: en Meded : Rijksinst. Visscher. Ond. (August 1941).

sijdschrift van de Neder: Mala: Ver: 7, Nos. 1 and 2, 12 (1942).

\section{The Anti-Chromatic Reflex}

IT has long been a matter for surprise that the eye appears to be so perfectly achromatized. It was this which led Euler to conclude that the construction of achromatic lenses must be possible, and in consequence the optician Dollond sought for a method, and thus invented the use of negative flint lenses in association with positive crown glass ones. The celebrated cobalt-blue glass experiment and many others amply demonstrate the fact that the lens system of the eye is uncorrected for colour. It was this fact that presumably led to the remark, which is often ascribed to Helmholtz, that if a lens maker turned out so inferior a lens as that of the eye he would soon be out of business.

Actually the performance of the eye as used in normal vision is of a very high order. Achromatizing the eye by means of a suitable combination of crown and flint glasses improves visual aeuity to a very slight extent only. The same is true when monochromatic light, for example sodium light, is used for visual purposes. Further, the resolving power of the eye is only slightly inferior to that of an apochromatic microscopic objective of the same focal length and aperture. But in one important respect the lens system of the eye is greatly superior to such a microscopic objective, namely, in its angle of view, for this in the case of the eye exceeds $100^{\circ}$ from the optic axis.
Many explanations have been offered in the past for the absence of coloured fringes from the retinal image. But none of these has proved to be satisfactory. The experiments which I have reported previously, in which micro-stimuli have been employed $^{1,2}$, have now led to the discovery of a nervous reflex which has the effect of eliminating the coloured fringes produced by the chromatic aberration of the eye: Because of this effect, it has been called 'the anti-chromatic reflex'. This reflex consists of two apparently separate mechanisms, one for dealing with the yellow fringe, and the other for dealing with the blue one; these are the colours of the fringes normally present in the emmetropic eye. In the uncorrected myope the fringes may be red and blue-green, and in the uncorrected hypermetrope they may be green and purple, or even blue-green and red. In these conditions the anti-chromatic reflex will probably fail to eliminate the fringes, so that they will be visible to the observer.

The mode of operation of the reflex may be explained by taking an example. Suppose the object looked at to be a white dot on a black background, then the image formed on the retina, owing to the chromatic aberration of the lens system of the eye, will consist of a bright yellow dot surrounded by a blue halo of low intensity. The anti-chromatic reflex will now convert the yellow dot into a white one, and at the same time the blue halo will be replaced by black; thus the original appearance of the object will be restored.

It is hoped to publish further details of this reflex shortly.

Physiological Department,

H. HARTRIDGE.

St. Bartholomew's Hospital Medical School, c/o Zoological Department,

University, Cambridge. Aug. 1.

1 Hartridge, H., Nature, 155, 391 (1945). 2 .Hartridge, H., Nature, 155, 657 (1945).

\section{Early Observation of Antibiotic Action}

IN his book "Essays on the Floating-Matter of the Air" (1881), the physicist John Tyndall describes experiments which he carried out in 1875 refuting the doctrine of spontaneous generation of life. In the course of these experiments tubes of organic infusions were infected with organisms after exposure to the atmosphere. A number of cases occurred when such tubes, which were turbid and swarming with bacteria, became covered with Penicillium glaucum, three unspecified kinds being noticed. The bacteria in these tubes lost their translatory power and fell to the bottom, leaving the liquid between them and the superficial layer clear. Tyndall ascribes this to the success of the moulds in the struggle for existence and notes that access of oxygen to the body of fluid must have been hindered. He did not, however, test the clear liquid for its capacity to support newly implanted bacterial life. It is interesting to speculate upon what the consequences might have been had Tyrdall allowed himself to be drawn from his main investigation.

Industrial Health Research Board, C. N. Davres.

Medical Research Council, c/o London School of Hygiene, Keppel Street, London, W.C.1. 